\title{
Experiencing the Production of Sounds
}

\author{
Matthew Nudds
}

In a recent book Jonathan Rée tells of how as a child he used to wonder which would be worse: to lose one's sight or one's hearing? Much worse, he concluded, to lose one's sight, since

\begin{abstract}
Sounds seemed to me to be nature's waifs and strays: they did not fit into the familiar world of physical things, and they could not be tracked down by my other senses either ... They were not part of the material world, and they had no weight to them, no substance. Is it surprising that I thought I could happily do without them? (Rée 1999: 19).
\end{abstract}

Whether or not we would be happy to do without sounds, the idea that our experience of sounds is of things which are distinct from the world of material objects can seem compelling. All you have to do to confirm it is close your eyes and reflect on the character of your auditory experience.

In what follows I will describe the features of our auditory experience which can lead one to think of sounds in this way. I will then describe a way in which we can experience sounds to be part of the material world. Since this is a kind of experience that essentially involves more than one sense, I will end by drawing some conclusions about how we should think about the senses.

Strawson, in his well known discussion of auditory experience, claims that we can adequately characterise our auditory experience in terms of auditory features alone, that purely auditory experience is the experience of what he calls a 'nospace world'. It is obvious, he says, that 'where experience is supposed to be exclusively auditory in character, there would [not] be any place for spatial concepts ... The only objects of sense-experience would be sounds. Sounds ... have no intrinsic spatial characteristics: such expressions as "to the left of", "spatially above", "nearer", "farther" have no intrinsic auditory significance' (1959: 65).

Since we think of the material world as a spatial world, if Strawson is right that our auditory experience is not intrinsically spatial then it is unsurprising that sounds can seem to be in a world apart from the material world rather than part of it.

European Journal of Philosophy 9:2 ISSN 0966-8373 pp. 210-229 @ Blackwell Publishers Ltd. 2001. 108 Cowley Road, Oxford OX4 1JF, UK, and 350 Main Street, Malden, MA 02148, USA. 
Why does Strawson think it obvious that sounds have no intrinsic spatial properties and hence that there is no place for spatial concepts in our characterisation of our auditory experience? Such a claim might strike one as simply mistaken, resting either, one might think, on an overly thin conception of auditory experience or on an overly thick conception of what it is to have spatial properties. One can, after all, hear sounds as coming from particular directions, or as occupying certain places; even with your eyes closed it is possible to tell that the voice of someone calling you is coming from over there, and as a result you can hear where they are. Of course, one would have to admit that the auditory world is spatially impoverished relative to the visual world; sounds do not have the spatial dimensions of the material objects of vision. But it doesn't follow from that that our experience of sounds is the experience of a no-space world.

In claiming that spatial properties have no auditory significance, Strawson is not denying that we can hear sounds as having a location but our doing so is, he says, explained by 'the existence of correlations between variations of which sound is intrinsically capable and other non-auditory features of our sense experience ... the de facto existence of such correlations is a necessary condition of our assigning distances and directions as we do on the strength of hearing alone.' So hearing sounds as coming from certain directions is not inconsistent with the claim that spatial properties have no auditory significance. But suppose someone were simply to deny this? What is it about auditory experience which warrants Strawson's conclusion? He clearly thinks that there is a contrast between auditory experience and visual experience (which is intrinsically spatial). The visual field, he says, 'is necessarily extended at any moment, and its parts must exhibit spatial relations to each other' (p. 65). So although a purely visual concept of space might be 'impoverished compared with our own ... it [is not] an impossibility. A purely auditory concept of space, on the other hand, is an impossibility' (pp. 65-6). ${ }^{1}$ There is, then, some contrast between visual experience, in particular the experience of a visual field, and auditory experience, in virtue of which it is correct to say that visual experience is intrinsically spatial and auditory experience is not.

In saying that vision involves a visual field one needn't be committed to any particular theory of perception; in particular one needn't accept a sense datum theory according to which the visual field is constituted by some mind-dependent array of colour patches of which the subject is aware and through which she becomes aware of the world. The claim that vision involves a visual field can instead be understood to be indicating certain phenomenological features of visual experience, in particular the fact that at any time we are aware both of objects and of a region of space within which we experience these objects to be, and which we experience as the potential location of objects. Such features can be identified independently of any particular theory of perception. M.G.F. Martin provides a nice description of the features in virtue of which the claim is true:

we can think of normal visual experience as experience not only of objects which are located in some space, but as of a space within which they are located. The space is part of the experience in as much as one is aware of 
the region as a potential location for objects of vision. This is not to say that one can actually experience all sub-regions of a visual space at one time . . o objects occlude each other. The occluded areas of the visual scene count as part of the visual space in the sense that one could come to be aware of something at that location without altering the limits of the visual field provided by the angle of vision at that time. An area can come into view simply by a re-arrangement of things within the field, rather than by changing the field itself (Martin 1992: 199).

He illustrates this with an example:

Consider the case of looking at ... a polo mint ... head on. One is aware of the various white parts of the mint arranged in a circle, and aware of how they are related to each another. One is also aware of the hole in the middle of the mint, and that that hole is there in the middle. If one was not aware of the hole one would not see the mint to be a ring-shape rather than a circle. Nothing need be perceived within the hole. One is aware of the hole as a place where something potentially could be seen, not as where something is actually seen to be (p. 199). ${ }^{2}$

I think it is this aspect of our visual experience that leads Strawson to claim that visual experience is intrinsically spatial. But what about auditory experience? In our experience of sounds are we aware of the space in which we hear sounds in anything like the same way as the way we are visually aware of space? The answer, I think, is obviously no. But some care needs to be taken in spelling out exactly why not. It doesn't follow, for example, from the fact that there is nothing in our auditory experience analogous to the bounded field of vision: we are not auditorily aware of there being any boundary to the region of space within which we can potentially hear sounds in the way that we are aware of there being a boundary to visual space, and there is no obvious way to draw a contrast between sounds which fall within and sounds which fall outside the auditory field. But the absence of such a boundary does not itself provide us with grounds for denying the intrinsic spatiality of sounds since it could still be the case that there is a region of space of which we are auditorily aware as a potential location of sounds: it's a region of space centred on the head and stretching out all around for an indeterminate distance. We can hear sounds as falling within this region of space, and we can be aware of many sounds simultaneously occupying different places within this space, and of the spatial relations between them. We are aware too that there are places where we cannot actually hear any sounds, but where we could potentially hear sounds. So we are auditorily aware of a region of space within which we could potentially hear sounds which is analogous to our visual awareness of a region of space as a potential location for objects of vision. There is an auditory space which is just like visual space, except that it is stretched so as to be boundless.

But it is not simply the existence of a bounded space which distinguishes the 
spatial features of auditory and visual experience. Whilst it is true that there is a space within which we can potentially hear sounds, there is nonetheless a difference between the way that one is visually aware of places where something potentially could be seen and the way that one is auditorily aware of places where something potentially could be heard. In fact, there's a sense in which one is not auditorily aware of places where something could be heard at all. In the case of vision, we can distinguish between having an experience of there being nothing at a place where we could experience something, and not having an experience of anything in a place we could experience something; between, that is, being aware that nothing is there and being unaware of anything there. In being aware of the hole in the polo mint one has an experience of a place at which there is nothing one is aware that nothing is there. In vision, one is experientially aware of places at which one could experience things to be. One is not aware of places which fall outside of the visual field as places at which one could experience things to be, although of course it may nonetheless be true that one could experience things to be in those places if one were to, e.g., turn one's head.

It is this visual awareness of places where there is nothing which has no auditory equivalent. We are simply not auditorily aware of empty places - there's no difference between not experiencing a sound at some place, and experiencing no sound there. One may hear nothing at some place, but in doing so one never comes to be aware of a place at which there is no sound - one is simply unaware. We can imagine a kind of spatial hearing deficit which prevents one from hearing anything at a particular place relative to oneself. In such a case it would no longer be true that one could potentially hear sounds from that place, and yet such diminution of the auditory field would not be apparent within one's auditory experience. That one could not hear sounds there would not be something of which one was experientially aware.

It is this, I suggest, that Strawson has in mind when he claims that visual experience is, whereas auditory experience is not, intrinsically spatial. It might be objected that, if this is what Strawson has in mind, it does not establish his conclusion. Drawing this contrast between visual and auditory experience doesn't show that sounds are not intrinsically spatial because there could be kinds of experience which have a different spatial structure to that of vision and yet which are still spatial. In fact, there are kinds of experience - tactual experience, for example - which we think are, or at least can be, intrinsically spatial and whose spatial structure contrasts with that of visual experience. It doesn't generally follow that an experience is non-spatial because it lacks the spatial structure of visual experience.

Such an objection would miss the point. In characterising the contrast between auditory and visual experience in the way that I have I am attempting to draw attention not merely to the fact that auditory experience has a different spatial structure, but that it has a structure that is non-spatial. We are visually aware of the space within which we see things in a way that we are not auditorily aware of the space in which we hear sounds. When we see (or seem to see) something, we see it as occupying or as located within a region of space; when we hear (or 
appear to hear) a sound we simply hear the sound, and we don't experience it as standing in any relation to the space it may in fact occupy. ${ }^{3}$

That is, I think, sufficient to establish the claim that our auditory experience is not intrinsically spatial, but the claim is further supported by the fact that the objects of auditory experience - sounds - themselves appear to have spatial properties in a way that is contingent, and need have no spatial properties at all. In saying that sounds need not have spatial properties, or have them contingently, I mean that one can hear a particular sound without hearing it as having any spatial properties (as when, say, one hears a ringing in one's ears), and that some sounds which we hear as having spatial properties can lose them. One might hear a sound, a low rumbling say, which initially one hears as coming from a certain direction but which, as one listens, one ceases to hear as coming from anywhere. The same thing can happen in reverse: a sound that initially appears not to come from anywhere can gain an apparent location. We shouldn't think of such cases as simply a matter of a sound's spatial properties becoming more or less determinate. Although sometimes sounds can surround or engulf one, so that they appear to have no determinate location (the sound of an audience applauding around you, for example) many sounds which have no apparent spatial properties do not sound like that. ${ }^{4}$

This is reflected in the way we identify or individuate sounds. We do not individuate sounds spatially; it follows that sounds can maintain their identity even when they lose their spatial properties. Suppose that outside in the street you hear a bulldog and a pekingese start to fight; you hear the whole thing and can tell exactly, from the growls and yaps, when one dog leaves off and the other begins. In such a case you can hear the sounds made by both dogs, and you can selectively attend to either; but there seems nothing spatial about picking out and attending to one sound rather than the other: you may not be able to tell very much at all about where the two dogs are..$^{5}$ Similarly, you might single out and attend to the sound of the oboe when listening to a piece of orchestral music without in any way being able to distinguish its location from the location of the other instruments that you can hear. In both cases you can identify and selectively attend to a particular sound non-spatially.

Another illustration of the non-spatial way we identify sounds is provided by a phenomenon known as 'the auditory stream effect'. To produce this effect, listeners are presented with an endlessly repeated sequence of six different tones, alternating three high ones and three low ones. When the tones are presented slowly to the listeners they hear the sequence in the order in which they occur. When the tones are presented at a faster rate the listeners no longer hear the tones in the correct order, but instead hear two streams of tones, one containing the repeating cycle of the three low pitched tones, the other the cycle of high pitched tones. The single sequence appears to break up into two different sounds, ${ }^{6}$ and yet there is no apparent change in the spatial properties of the sounds; throughout, the sounds may appear not to have any spatial properties at all (Bregman 1990: 17-18).

Given this, I think it's right to say that sounds are only contingently spatial. 
That's not merely to say that, like the material objects we perceive, they have the particular spatial properties they do contingently, but that they could lack spatial properties altogether. That's not true of the objects of vision. Although we can see something move, and so see its spatial properties change, we cannot see it lose them altogether; so the objects of our visual experience, like our visual experiences of them, are spatial. This is not true of sounds. We can hear a sound without hearing it to have any spatial properties at all. When we do experience a sound to have spatial properties, that it has them at that time appears equally contingent; we can easily suppose that we could have heard that very sound without hearing it to have the spatial properties we actually hear it as having: although in fact we hear it to be located, it might not have been. ${ }^{7}$ Not only can we imagine a world of sounds which is a no-space world but, I suggest, we can imagine the actual world of sounds as a no-space world.

When we come to reflect on our auditory experience, on what sounds are like, then it can seem that their connection with the objects of sight and touch is a precarious one. Sounds may appear to be, as Strawson says, correlated with the material world, but they do not appear to be part of it. We can imagine a world of sounds which is dissociated from the world of material objects; we can imagine, too, the sounds we actually hear apart from the things that we see and touch. There appears to be nothing intrinsic to the sounds that we actually hear to connect them with the world of sight and touch.

Compare this with our experience of the objects of sight and touch. It's much harder to imagine the visual world - the world of seen objects - as dissociated from the tactual world. We are visually and tactually aware of intrinsically spatial objects that we perceive to occupy a single integrated spatial world, and so in imagining the world of sight dissociated from the world of touch we must imagine something quite different from our ordinary experience; there's no mere correlation between the objects we see and feel: they are one and the same; you can see the very same object that you feel, and you can experience it as the same object. ${ }^{8}$ When one sees and feels a particular object in this way it's not possible to imagine the very object one feels apart from the object one sees; there appears to be a unity to the objects of sight and touch. So whilst sounds appear not to be part of the material world, the same is not true of the objects of sight and touch.

So far I have been talking about what our auditory experience is like and I have been assuming, implicitly, that in attending to one's auditory experience one attends to that alone and one ignores, or excludes as much as possible, the experiences of the other senses (by, for example, shutting one's eyes). But is this the right way to go about things? Is what is true of auditory experience alone true of the experience we have of sounds when we use our hearing together with sight and touch? We tend to assume that it is. 
In The Guermantes Way, Proust describes Swann as he sits quietly waiting for Saint-Loup, reflecting, as he does so, on the sounds that he can hear:

I heard the tick of Saint-Loup's watch, which could not be far away. This tick changed place every moment, for I could not see the watch; it seemed to come from behind, from in front of me, from my right, from my left, sometimes to die away as though it were a long way off. Suddenly I caught sight of the watch on the table. Then I heard the tick in a fixed place from which it did not move again. That is to say, I thought I heard it at this place; I did not hear it there, I saw it there, for sounds have no position in space (Proust 1925: 72).

Just such an effect can occur when listening to someone speak from some distance in a crowded or echoing room: when looking at them speak you may hear the voice as coming from the speaker - you both hear and see where the source of the sound is; but when your eyes are turned elsewhere you may no longer be able to tell where the voice is coming from. With your eyes again fixed on the speaker, and on the movement of her lips, a clear sense of the source of the sound will return. This effect can occur even when the sound alone has no apparent location as when, for example, the speaker's voice is relayed to speakers positioned all around the room. You might have had a similar experience; it's one of a number of perceptual phenomena which reflect the way in which vision can dominate auditory perception. ${ }^{9}$ You will doubtless be familiar with another example: the ventriloquism effect. The ventriloquism effect occurs when a voice in one place that of the ventriloquist - is heard to come from a different place - the mouth of a dummy. By keeping her own mouth shut and directing our attention to the dummy whose mouth, eyes, lips, and other movements are manipulated in synchrony with what she is saying, the ventriloquist is able to take advantage of the interaction between the viewer's different senses to create the illusion that it is the dummy who is speaking: to the audience it can seem as if it is the dummy that is producing the sounds. Although there is a spatial discrepancy between the visual and auditory sources of the perceived event, when one experiences the ventriloquism effect one hears the sound to come from the direction of the visual source, and one perceives no discrepancy between what one perceives with different senses.

The persistence of the ventriloquism effect has been experimentally tested (Warren et al. 1981). In the experiment, subjects (whose heads were held in position) viewed a monitor on which was played a video of a talking head. A soundtrack was played through a separate loud-speaker whose position relative to the monitor could be varied. Subjects were asked to judge whether the voice they could hear was that of the talking head and to indicate the direction in which they perceived it or, if they perceived them to be different, the direction in which they could see the head and the direction from which they could hear the voice. The experimenters varied the setup so that sometimes the recorded voice matched the mouth movements of the head; at other times they introduced a discrepancy 
between the voice and the mouth movements either by means of a short time delay between the two or by playing recordings in which different words were spoken by the head on the video and played over the loud-speaker. The relative location of, and the distance between, the monitor and the speaker were also varied.

The (surprising) result of this experiment was that subjects often perceived a single event - a head speaking - when the voice and picture were perceived to correspond with one another even when the actual source of the voice was different to that of the head; and when asked to indicate the direction of the head and the voice they indicated the same direction, but got both wrong. That is, when asked in which direction they heard the voice to come from they indicated a position between that of the actual position of the voice and the actual position of the head (though much nearer to the actual position of the head); and when asked to indicate the direction in which they saw the head they indicated the same position as they did when asked the direction of the sound. When shown the head or played the voice separately and asked to indicate their position, subjects were generally accurate.

It is important to note that the ventriloquism effect is a perceptual phenomenon, and not the result of a judgement to the effect that what one sees is what one hears. The interaction of vision and hearing produces a change in the one's experience; the place a sound appears to come from when one simply hears the sound is different to the place it appears to come from when one both hears the sound and sees its source. One experiences a kind of perceptual illusion: it seems as though the sound is at the same place as the thing one sees - the talking head even when it is not. This is brought out nicely by the experiment. The subjects of that experiment, when asked what they could perceive, reported that they experienced a single event - a person talking - and they failed to report any discrepancy between what they perceived with different senses even when there was such a discrepancy. If these subjects were merely judging that they were perceiving a single event, and ignoring or setting aside certain discrepancies between what they perceived with each sense, then we would expect them to be aware, or capable of becoming aware, of the discrepancy. Yet when subjects were told of the discrepancy between their senses they were often unable correct their responses. And, in general, knowing that one is being tricked by a ventriloquist does not reduce the effect - you may be knowingly entertained by a ventriloquist's skill. Thus the phenomenon that I am describing displays 'the characteristic feature of the content of experience as opposed to the content of judgement in that [it] need not alter when additional information results in a judgement of a content incompatible with that of the experience' (Peacocke 1986: 156). All kinds of intersensory bias appear to display this characteristic feature. Consequently, the subjects of biased experiences find it very hard to correct their mistakes.

If the phenomenon is perceptual, then how should we characterise the resultant experience? How does the bi-modal experience differ from hearing alone, or from the kind of experience we have when we see a bad ventriloquist who is unable to produce the effect? It might be suggested that the result of experiencing the 
ventriloquism effect is that one simply experiences a change in the apparent location of what is perceived with each sense individually. In what follows I will argue that it would be wrong to characterise the change in one's experience as simply a change in the apparent location of what one perceives. There is a difference between, on one hand, hearing a sound as coming from the same place as an event one sees and, on the other, the kind of experience one has of the ventriloquism effect or, more generally, the experience one has of seeing someone speak. In general, when we perceive someone speaking whose voice we hear, we do not simply hear their voice as coming from the same place that we see them to be.

When we hear a sound we are often in no doubt about what produced it; not just what kind of sound it is, or what kind of thing produced it, but which particular happening did; this is something that we can perceive. We often see something happen and hear a sound, and we perceive the sound to have been produced by what we saw happen, we experience the production of the sound. ${ }^{10}$ In the experiment that I described, subjects experience the voice they hear being produced by the head that they see, they experience the head as responsible for the voice they hear. Similarly, when one experiences the ventriloquism effect, the voice one hears appears to be produced by the dummy; it's not just that one hears the voice as coming from the same place as one sees the dummy to be, one experiences the dummy and its mouth movements as responsible for what one hears.

What does it mean to say that we experience the production of sounds? We are familiar with experiences of seeing one event cause another, as Peacocke says:

anyone who sees the child's hand knocking over the tower of blocks, or a fork-lift truck as lifting a crate, has [experiences as of one event causing another]. These experiences would not be adequately characterised as seeing an event of one type following an event of another type. Rather, taking the experiences at face value, one would be disposed to judge that the child's movement caused the tower to fall over or to judge that rising of the fork-lift truck's arms caused the crate to go up (Peacocke 1986: 156). ${ }^{11}$

In the cases Peacocke describes the events are visually perceived and the experience of apparent causation between them is a visual experience; I am suggesting that we can have similar experiences as of causation between things perceived with different senses. When we see a dog bark and hear the sound it makes we don't just hear a sound as coming from the same place we see the dog barking; we perceive the dog to be producing the sound we hear. When we see a hammer striking an anvil and hear the sound of the blow we perceive the hammer blow as producing the sound. We need not restrict the examples to sight and hearing: we can feel something produce a sound we hear, too: when we feel a tuning fork vibrate and hear the noise it makes, it is plausible to claim that we perceive the noise as being produced by the fork's vibration.

These are all cases of perceiving some event followed by a sound, and of perceiving the sound to be produced by, or caused by, the event. This is something 
that we perceive, it is part of the content of our experience; these experiences would not be adequately characterised as hearing a sound to come from the same place as one sees something happen. If one takes one's experience of hearing someone one sees speak at face value, one would be disposed to judge that the person speaking is responsible for the sounds that one hears, that they are (or perhaps, more accurately, something they do is) producing or causing those sounds.

It might be objected that we can characterise the kind of experience I am describing without mentioning the experience of causation or production. The experience that I describe as the experience of something causing or producing a sound is really, it might be said, nothing more than the experience of hearing a sound to be located in the same place and to occur at the same time as an event we see, together with a judgement that what we see produces the sound that we hear. There is, however, a difference between hearing something to occur in the same place and at the same time as something we see happen, and perceiving a sound as being produced by something we see happen. Someone who denies that we have the kind of experience I am describing won't be able to mark this difference. One can often hear sounds at the same place as one sees something happening without it seeming to one that the sound is produced by what one sees happening. This is well illustrated by the - incredibly irritating - experience we have all had of the sound track of a film being slightly out of synchronisation with the pictures. Even when we hear the voice as coming from the same place as the person we see on the screen - when, for example, the soundtrack is in stereo - it doesn't appear to us that the person is speaking the words, that they are responsible for them; that's why the experience is so irritating. Although we hear the voice as coming from the same place as something we see happening, we don't hear it as being produced by what we see happening. What's missing here is not a judgement to the effect that someone we see is producing the sounds that we hear: knowing that the words we hear are being spoken by the person we see doesn't reduce the effect.

Someone might still object to my description of these experiences as experiences of causation for the reason that causation is not something that we can experience. Note that, in claiming that we have experiences as of one event causing another, I am not committed to any particular view of the nature of causation, nor even to denying that causation ultimately consists in regularities; so a general scepticism about the reality of causation is no reason to reject my claim. It might nonetheless be argued that our concept of causation is the concept of a kind of relation which we could not simply experience to be instantiated. Peter Menzies, for example, suggests that the counterfactuals involved in an instance of causation make it a relation that 'cannot plausibly be claimed to be an object of direct awareness' on the grounds that the truth of a counterfactual cannot be perceived (Menzies 1993: 202-3). The conception of a cause to which I am appealing, however, is not this very general philosophical concept; it is, rather, one of a whole range of causal concepts that feature in our everyday thought and language, concepts which include scrape, push, carry, knock over, squash, make 
and so on. ${ }^{12}$ For as long as we allow that people possess and use such concepts, and can apply them to things on the basis of perceiving the interactions between, then we should allow that causality, in this sense, can be perceived. People clearly do possess and use such concepts; Anscombe is right when she says:

As surely as we learned to call people by name or to report from seeing it that the cat was on the table, we also learned to report from having observed it that someone drank up the milk or that the dog made a funny noise or that things were cut or broken by whatever we saw cut or break them (Anscombe 1971: 69. Italics mine).

In claiming that we experience causation between events and sounds I am claiming no more than that we have experiences such as these. ${ }^{13}$

There is, I have been arguing, a difference between hearing the sound produced by something without seeing (or perceiving in some other way) whatever it is that produces it, and having the experience of a sound as being produced by something that you can see (or otherwise perceive). This latter experience is one that we can only enjoy as a result of using two different senses. We never simply hear something as producing a sound because we can't hear the sources of sounds apart from hearing the sounds that they make, and we never simply see sounds as being produced because we don't simply see sounds, but we can perceive sounds as being produced when we both see the source of a sound and hear the sound that it is producing. The experience of the production of a sound is, therefore, essentially bi-modal - it is an experience which essentially involves two (or more) senses. In the final section I will argue that this has consequences for how we should think about the nature of the different senses, and consider again the suggestion with which I began, that we don't experience sounds to be part of the material word. In the next section I consider objections to the claim that the experience is essentially bi-modal.

\section{III}

Someone might accept that we have experiences of the kinds that I am describing but claim that such experiences do not require the use of both hearing and vision. Clearly one cannot experience the production of a sound without hearing it, but it might be thought that one can experience something as producing a sound by hearing alone. We often talk of hearing the source of the sounds that we hear, of hearing the thing which produces the sound. So, for example, we often say that we can hear the dog barking as well as the dog's bark; and this doesn't appear simply to be a manner of speaking since we can think demonstratively about the sources of the sounds we hear. Many writers have drawn this conclusion. Campbell, in a discussion of perceptual demonstratives, claims that we can refer 'to an ordinary physical object' on the basis of hearing the sound that it produces. So when you hear a dog barking you can refer, using demonstratives such as 'that 
bulldog', to the source of the sound - the dog itself (Campbell 1997: 65). Similarly, Moreland Perkins thinks that one can be auditorily aware of a person, and that one's auditory awareness of that person is in part constituted by an awareness of the sound they make: 'hearing [his wife] speak from the kitchen, [a man] not only hears the sound she makes, he also, as we say, hears her: his ... awareness of his wife we conceive also to be auditory. But auditory awareness is also sensory awareness; so when he hears her voice his ... awareness of his wife is sensory awareness' (Perkins 1983: 12). These are examples of a purely auditory awareness of the source of a sound. We are aware of the source by being aware of the sound that it makes, and only through being aware of that sound. It is the kind of awareness of the source of a sound that you can have even when you don't see or otherwise perceive it.

If it is accepted that one can hear material objects, then it seems possible to explain the distinction between hearing a sound as produced and simply hearing a sound in a different way. Sometimes when one hears a sound one can also seem to hear whatever it is that in fact produces the sound, as when one hears a dog. This is not always true, though - often one simply hears a sound. Perhaps this difference has something to do with recognition. When one does not recognise the sound then one cannot be said to hear the object; when one does recognise it then one can be said to hear the object. Whether or not that is right, the fact that there is this difference might lead us to suppose that hearing a sound as produced is simply hearing the sound and an object which produced it in that way in which awareness of the object is partly constituted by awareness of the sound. If that is the correct explanation of our experience of the production of sounds then it is a purely auditory experience not essentially involving vision or any other sense. Vision might have a role to play in helping us recognise sounds, but it doesn't have the role that I claim it to have.

I don't want to deny that we can hear objects as well as the sounds that they make, but I don't think that that provides a satisfactory explanation of our experience of the production of sounds. One reason, I suspect, that such an explanation can seem attractive is a misconstrual of the relation between sounds and the objects which produce them. We shouldn't think that we can hear the sources of the sounds that we hear in virtue of the fact that sounds are properties or features of their sources. Several writers seem to endorse the view that sounds are sensible qualities of their sources, and sometimes we do talk as if they were: we talk, for example, of a floorboard creaking, or of a bell as having a mellow sound. Hearing a sound, according to this kind of view, can be hearing the source of a sound in the same way that seeing a shape is seeing the shape of something (of an object or surface). ${ }^{14}$ But sounds are not properties or features of their sources, and so we shouldn't think of our awareness of the source of a sound as being analogous to our awareness of an object whose shape we see. Unlike our awareness of the shape of an object, it is possible to hear a sound without hearing its source. Moreover, our usual way of thinking of sounds is as of things which are distinct from their sources. One of Newton's minor triumphs in the Principia was a derivation of the velocity of sound. To test his derivation he measured the time 
for an echo to return from the end of a colonnade in Neville's Court of Trinity College. Lacking anything resembling a stop watch, he adjusted a pendulum to swing in rhythm with the echoes of successively made sounds (Westfall 1980: 455-6). Newton used the pendulum to measure the time it took for a sound to travel from its source down the colonnade to a wall and then back again; he heard the particular sound that he had produced a moment earlier reflected back to him. Here we have an example of a sound existing even after the event which produced it ceases (we can suppose) to exist, and which moves independently of whatever produced it. It is also an example of a single sound being heard more than once: Newton re-encounters a particular sound, as he must do if he is to time its journey up and down the colonnade. Sounds, then, are particulars. Normally we think of events as things that, unlike objects, cannot be re-encountered. The fact that we can re-encounter sounds suggests that they are perhaps best thought of as kinds of objects, rather than as events; either way, not as properties. ${ }^{15}$

Given this, we should explain many cases of pure auditory awareness of the source of a sound as a kind of deferred ostension, as picking out the source of a sound via picking out the sound itself. Thinking of 'that car' might be equivalent to thinking something like 'the car which is actually producing this sound,' of 'that dog' as 'the dog which is actually making that noise' (c.f. Martin 1997: 93).

Whether or not one agrees with that suggestion, it remains the case that when one hears an object on the basis of pure auditory experience one does so by hearing the sound that it produces, but one does not hear it as producing that sound. In the kind of cases that I am interested in, we are aware of and can pick out the event we experience as producing the sound independently of hearing that sound, and we can be aware of the event picked out in this way as producing the sound we hear. It is that kind of experience which is essentially bi-modal.

\section{IV}

What, if anything, follows from all of this? I began with the idea that sounds can, on reflection, seem not to be part of or fit into the material world of sight and touch. Whilst that may well be true of our purely auditory experience of sounds, sounds heard without using other senses, it is not true generally. We can perceive sounds as being produced by events we see and feel and so to be interacting with the objects of sight and touch. These sounds appear to be as much a part of the material world as the objects we see and feel.

One way to bring out the way in which we ordinarily experience sounds as part of the material world is to consider what our experience of the world would be like without auditory experience. In a passage a little further on from the one I quoted earlier, Proust describes Swann contemplating just this possibility; the deaf man, he supposes, doesn't simply live in silence, his experience of what he sees is different: 
The highest waterfalls unfold for his eyes alone their sheets of crystal, stiller than the glassy sea, pure as the cascades of Paradise. Since sound was for him, before his deafness, the perceptible form which the cause of movement assumed, objects moved soundlessly now seem to be moved without cause; deprived of the quality of sound, they show a spontaneous activity, seem to be alive. They move, halt, become alight, of their own accord. Of their own accord they vanish into air like the winged monsters of prehistory ... the building which the deaf man looks out on from his window . . . is only so much scenery. If one day it should fall to the ground, it may emit a cloud of dust and leave visible ruins; but, less substantial than even a palace on the stage ... it will subside into the magic universe without letting the fall of its heavy blocks of stone tarnish the chastity of the prevailing silence ... (Proust 1925: 73).

The deaf man is not simply unaware of sounds, the way that he experiences the things he sees is different too - he no longer experiences the production of sounds. The person who can hear, on the other hand, experiences the sounds made by the things they see as part of the causal structure of the visible world.

In thinking about how sounds relate to the objects of sight and touch we don't just learn about how we experience sounds as fitting into the world; we can discover something about the nature of the different senses. I have described how we can have experiences of sounds as being produced or caused by things we see; this is a kind of experience which essentially involves more than one sense. That there are such experiences makes puzzling a tendency we have when thinking about the senses to think of them as distinct 'windows' through which we experience the world.

In perceiving the world we perceive many things as having properties and standing in relations which we actually perceive with different senses. I have been discussing our perception of the relations between material objects and events, and sounds, a relation we perceive using hearing and touch or vision, but we perceive things using sight and touch, and with various combinations of all the senses. Just as we can perceive sounds to be part of the same world as the things we see and feel so, in general, the properties that we perceive using different senses can appear to us to belong to the very same objects. We perceive a single, unitary, world: in our day to day interaction with the world we don't distinguish its objects and features in terms of the senses using which we perceive them.

But suppose, in a more contemplative mood, we step back from our day to day interactions with things and instead reflect on our experience of them. When we do so, does our experience become fragmentary? Do we come to be aware of five distinct experiences associated with each of our senses? Any temptation that we have to think our experience does derives from the way we tend to think about the senses in isolation from one another. We tend to think that if you want to know what visual experience is then you should reflect on the experience that you have when watching a film or when contemplating a painting; we tend to 
think that if you want to know what touch is like then you should imagine what the experience of a blind person is like as they explore a sculpture; and so on. This way of thinking about experience goes together with a particular conception of the senses. We tend to think of the senses as distinct things: as five different perceptual inlets to the mind. We tend to think that each of the senses is, in some significant way, distinct from and independent of the rest, that each sense is separable from and can function independently of the others. And we tend to think that our perception of the world is the result of the combined use of whatever senses we have, so that what we perceive is the sum total of what each sense alone provides. ${ }^{16}$

Someone who holds this conception of the senses is likely to see one interpretation of Molyneux's question as central to our understanding of them. In 1688 William Molyneux wrote to Locke (Locke 1689: II, ix, 35) and asked him whether a man who was born blind and who had learnt to distinguish shapes on the basis of touch could, if his sight were restored, say which shape was which by vision alone without having touched them. Molyneux thought not, and Locke - and later Berkeley - was inclined to agree with him. There is much disagreement about what question - given their background assumptions, conception of experience, and so on - Molyneux was asking Locke, and about what question Locke took him to be asking, ${ }^{17}$ and there are differing views as to what general problem we should take Molyneux's question to be raising. Most recent authors have understood it to raise a problem for us about the relation between sight and touch, about how we can tell that what we see is the same as what we touch.

If the senses are distinct then that question is perfectly reasonable: an account of the senses must say something about how the distinct inlets flow together and merge, about how the perceptions of different senses are integrated with one another. But it's a question that only really makes sense if we assume that the five senses are distinct things producing perceptions we have somehow to merge and about which it can be asked whether they are the same or different. This is an assumption that Berkeley explicitly held, and which is implicit in more recent discussions; it's an assumption I think that we should reject.

In this paper I have tried to show that reflecting on our experiences of different senses in isolation from one another distorts the way our experience seems to us to be: it misses aspects of experience present only when the senses are used together. That, I suggest, gives us a reason to reject the assumption that the senses are distinct things; it also raises a problem for the account of the senses suggested by Berkeley and for the kind of account typically favoured by a sense datum theorist. ${ }^{18}$ The problem is slightly different in each case. Berkeley thinks that we perceive instances of qualities - what he calls sensible ideas or qualities - and that there are different kinds of quality specific to each of the senses. We don't, he says,

immediately perceive by sight any thing beside light, and colours, and figures: or by hearing, any thing but sounds: by the palate, any thing beside tastes: by the smell, beside odours: or by the touch, more than tangible qualities (Berkeley 1734: 175). 
Objects are just collections or congeries of these sensible qualities and there is nothing wrong with the idea that audible ideas should be grouped together with visible ones. One problem that the fact that we can experience sounds as produced by objects raises for Berkeley is, therefore, to locate some further quality which results from the collection of audible and visible ideas together, but which comes from neither. Now, there's no reason to think that Berkeley couldn't simply add to his list of sensible qualities, so the experience of the production of sounds may not raise any very serious difficulty for this view of experience. Were he to do so, however, it would be much less plausible to claim that we can identify each of the senses with an awareness of a certain kind of sensible quality, and so less plausible to claim that there are distinct kinds of experience associated with each of the senses.

A sense-datum theorist, in contrast, takes our perceptual experience to be constituted by an awareness of mind dependent objects (which themselves instantiate properties). On this kind of view it is usually supposed that we are not aware of the same particular object with more than one sense, and that the objects of different senses are different in kind. The experiences of different senses are distinct because they are constituted by an awareness of distinct objects, and they are different in kind because constituted by an awareness of different kinds of object. The problem that our experience of the production of sounds raises for this kind of view is that it is an experience of a feature of an object that is both seen and heard. In the face of this the sense datum theorist might simply give up the claim that the experiences of different senses are always constituted by an awareness of distinct particular objects; were they to do so, however, it would no longer be plausible to claim that each of the five senses simply consists in the awareness of a particular kind of object and the sense datum theorist would have to provide some other account of the senses.

In this paper I have concentrated on our experience of sounds. Related phenomena occur with the objects of the other senses. When we reflect on our experience of the world we don't discover our experience to be fragmentary; just as we experience a unitary world, so our experience of the world is unitary. If I am right then the real problem of the senses is not how they are related to one another, but why, given the character of our experience, we distinguish five senses in the first place. ${ }^{19,20}$

\section{Matthew Nudds}

School of Philosophy

Birkbeck College

University of London

Malet Street, Bloomsbury

London WC1E 7HX, UK

m.nudds@bbk.ac.uk 


\section{NOTES}

1 A visual concept of space would be impoverished, Strawson suggests, because our conception of space is the conception 'of a spatial system of objects, through which oneself, another object, moves, but which extends beyond the limits of one's observation at any moment, or, more generally, is never fully revealed to observation at any moment'; it is a conception of something objective - capable of existing independent of one's experience of it. Strawson suggests that a conception of space in this sense cannot be given purely visual significance; it is, rather, a theoretical conception (c.f. Evans 1985a). One can reject the claim that a purely visual conception of space is impoverished without rejecting the contrast that I'm about to draw. That is, one might claim that visual experience has a richer spatial content than Strawson allows without having to claim that auditory experience is spatial.

2 Martin goes on to contrast this feature of visual experience with tactual experience. He points out that it does not apply to many examples of touch. When one grasps the rim of a cup with one's fingers one can become aware of the shape of the cup, that it is circular, even though one comes into contact with it only at the points where one's fingertips touch it. Here we can draw a contrast between the way in which one is aware of the points of the rim between the points of contact, and the points of contact themselves. Does the space within the rim fall within a tactual field? Are they potential objects of tactual awareness? In the case of vision (and of hearing) we might answer this by asking whether we could experience something there. See Martin 1992: 200.

3 In claiming on this basis that sounds are not intrinsically spatial I am saying nothing inconsistent with Evans' account, in The Varieties of Reference, of the spatial content of auditory experience (compare Evans here with Malpas 1968). Our auditory experience, on his account, has spatial content in virtue of its connections with spatially directed behaviour; in virtue, that is, of connections to something extrinsic to our auditory experience, extrinsic, one might say, to its sensory content. Evans is attempting to explain in virtue of what we hear sounds as having locations, coming from certain directions, and so on. His explanation of that is quite consistent with the fact that our auditory experience has the features that I am describing. See Evans 1982: 156-7.

4 This feature of sounds shows up in imagination too. You can imagine hearing a sound, of a particular piano recital, for example, without imagining the sound to come from anywhere. The same is not true of visualising: when you imagine seeing something you imagine it spatially presented to some - not necessarily your own - point of view.

5 The example is from Campbell 1997: 65-66.

6 Subjects were unable to focus their attention on both streams at the same time: when they focussed on one, the other was heard as vague background; as a consequence, listeners were unable to report the order of the six tones taken together, although they could report the order of the high or low tones individually.

7 This conclusion might prompt the question: is the non-spatiality of sounds a consequence of the nature of our experience of sounds or of the nature of sounds themselves? In the case of vision we think of both the objects and the experiences as being spatial: the objects because they form part of the furniture of a spatial world, the experience because it is able to provide us with an intrinsically spatial awareness of that world. But even if visual experience had been non-spatial it could have provided us with an awareness of objects which are actually spatial.

${ }^{8}$ Which isn't to say that we couldn't have visual and tactual experiences which were 
dissociated from one another (we sometimes in fact do have them) - just that such experiences would be very different from the kind of experience we usually actually have. In particular, if one actually sees and touches an object in the way described, one couldn't have that same experience of an object and yet one's sight and touch be dissociated.

9 Similar 'intersensory bias' effects can occur with various combinations of senses; another example - from the laboratory - is visual capture, in which the felt position of one's finger or hand is strongly biased in the direction of its prismatically displaced visual image. For some psychological studies see Welch 1978 and Stein and Meredith 1993, Ch. 1.

10 In saying that we perceive the production of the sound I do not merely mean that we experience something that is, in fact, the production of the sound, but that we experience something as the production of the sound. In general, when I talk of experiencing the production of a sound I mean it to be understood in the latter sense.

11 Peacocke refers to the work of Michotte (see Michotte 1963, esp. appendix 2); and see Bruce and Green 1990: 333 for a discussion and other references. Bruce and Green are sceptical of Michotte's claim that causality is directly perceived, but not of the claim that we do have experiences of the sort described by Michotte. It's just that they think that an explanation of our experience's representing causality must appeal to computations or inferences performed by the visual system.

12 This list is from Anscombe 1971: 68-9.

13 Anscombe points out that the apparent perception of such things may only be apparent: we may be deceived by false appearances. For further discussion of these issues, see Armstrong 1997: $211 \mathrm{ff}$.

14 This seems to be what David Sanford thinks 1976: 192-3). He, like Perkins, takes the relation between sounds and objects with respect to hearing to be analogous to that between colours and objects with respect to sight.

15 Someone might object as follows: What Newton measured was the time that it took a sound wave to travel down the colonnade and back; in hearing the echo he didn't hear the same sound again, he heard a distinct sound which resembled the original. Such an objection, it seems to me, mis-characterises the way we usually count sounds: we make a distinction between echoes and sounds which merely resemble one another (if I shout and I hear a similar shout a little later, I don't think of it as an echo if it turns out that the second shout I hear was made by someone else) which can be explained by supposing that echoes are re-encounters with particular sounds. It's true that Newton measured the speed of a sound wave, but he did so by measuring the time it took a sound to travel down the colonnade and back.

16 This is a conception of the senses made explicit by Berkeley. See Berkeley 1732.

17 Did they, for example, take it for granted that the blind man would be able to see shapes when his sight was restored so that the question was about recognising shapes? Or was it a question about form perception - about whether he would be able to see shapes at all? For an excellent discussion, see Martha Brandt Bolton 1994. For discussions of Molyneux's question in a recent context see Evans 1985b, Peacocke 1982: ch.2, Campbell 1996 and, for a different conception of the problem, Eilan 1993.

18 Many contemporary accounts of the senses are essentially variants of Berkeley's view or of the sense datum view. These problems are problems for these contemporary accounts too.

19 It might be objected that the distinction between five senses is a distinction made by common sense, and that common sense is mistaken: scientific investigation shows us that there are really more and different senses than those recognised by common sense. There 
isn't space to provide a detailed response to this kind of objection; however, I don't think that the fact that science shows, e.g., that our common sense category of touch is subserved by a variety of distinct sensory mechanisms is sufficient to show that our commonsense category is mistaken or empty. It may, though, be sufficient to show that our common-sense concept of touch is not the concept of a kind of sensory mechanism.

20 Earlier versions of this paper were read to audiences in Warwick and St Andrews. I am grateful to members of those audiences for their comments. I am especially grateful to Mike Martin, Tim Crane, Matthew Soteriou, Hanna Pickard, Fraser MacBride, Naomi Eilan, Tom Crowther and an anonymous referee for helpful comments.

\section{REFERENCES}

Anscombe, E. (1971), 'Causality and Determinism', in Causation and Conditionals, edited by E. Sosa. Oxford: Oxford University Press.

Armstrong, David M. (1997), A World of States of Affairs. Cambridge: Cambridge University Press.

Berkeley, George (1732), 'An Essay towards a New Theory of Vision', in Berkeley Philosophical Works, edited by M. R. Ayers. London: Dent.

Berkeley, George, (1734), 'Three Dialogues Between Hylas and Philonous', in Berkeley Philosophical Works, edited by M. R. Ayers. London: Dent.

Brandt Bolton, Martha, (1994), 'The Real Molyneux Question and the Basis of Locke's Answer', in Locke's Philosophy: Content and Context, edited by G. A. J. Rogers. Oxford: Clarendon Press.

Bregman, Albert S. (1990), Auditory Scene Analysis. Cambridge, Mass.: MIT Press.

Bruce, Vicki, and Green, Patrick (1990), Visual Perception: Physiology, Psychology and Ecology. London: Lawrence Erlbaum Associates.

Campbell, John (1996), 'Molyneux's Question', in Perception, edited by E. Villanueva. Atascadero: Ridgeview.

Campbell, John (1997), 'Sense, Reference, and Selective Attention', Proceedings of the Aristotelian Society, Supplementary Volume LXXI.

Eilan, Naomi (1993), 'Molyneux's Question and the Idea of an External World', in Spatial Representation: Problems in Philosophy and Psychology, edited by Naomi Eilan, Rosaleen McCarthy, and Bill Brewer. Oxford: Blackwell.

Evans, Gareth (1982), The Varieties of Reference. Edited by J. McDowell. Oxford: Clarendon Press.

Evans, Gareth (1985a), 'Things Without the Mind', in Collected Papers. Oxford: Clarendon Press.

Evans, Gareth (1985b), 'Molyneux's Question', in Collected Papers. Oxford: Clarendon Press.

Locke, John (1689), An Essay Concerning Human Understanding. Edited by P. H. Niddich. Oxford: Clarendon Press.

Malpas, R. M. P. (1968), 'The Location of Sound', in Analytical philosophy: Second series, edited by R. J. Butler. Oxford: Blackwell.

Martin, M. G. F. (1992), 'Sight and Touch', in The Contents of Experience, edited by T. Crane. Cambridge: Cambridge University Press.

Martin, M. G. F. (1997), 'The Shallows of the Mind', Proceedings of the Aristotelian Society, Supplementary Volume LXXI. 
Michotte, A. (1963), The Perception of Causality. Translated by Heath, P. New York: Basic Books.

Peacocke, Christopher (1982), Sense and Content. Oxford: Clarendon Press.

Peacocke, Christopher (1986), Thoughts: An Essay on Content. Oxford: Basil Blackwell.

Perkins, Moreland (1983), Sensing the World. Indianapolis: Hackett.

Proust, Marcel (1925), The Guermantes Way. Translated by C. K. Scott-Moncrieff, Remembrance of Things Past/Marcel Proust; 3-4. London: Chatto and Windus.

Rée, Jonathan (1999), I See a Voice. London: Harper Collins Publishers.

Stein, Barry E., and Meredith, M. Alex (1993), The Merging of the Senses. Cambridge, Mass.: MIT Press.

Strawson, P. F. (1959), Individuals. London: Methuen.

Warren, D. H., Welch, R. B. and McCarthy, T. J. (1981), 'The role of visual-auditory "compellingness" in the ventriloquism effect: Implications for transitivity among the spatial senses'. Perception and Psychophysics 30: 557-64.

Welch, R. B., and Warren, D. H. (1978), 'Intersensory interaction', in Handbook of Perception and Human Performance, edited by K. Bluff and L. Kaufman.

Westfall, Richard S. (1980), Never at Rest. A Biography of Isaac Newton. Cambridge: Cambridge University Press. 